\title{
Interview with Erin Carrie and Rob Drummond of The Accentism Project
}

\author{
Conducted by Laura L. Paterson
}

Dr Erin Carrie is a Senior Lecturer in Linguistics at Manchester Metropolitan University, UK. She specialises in sociolinguistics, language variation and change, and language attitudes. Dr Rob Drummond is also a Reader in Linguistics at Manchester Metropolitan University and is Head of Youth Language at the Manchester Centre for Youth Studies. They have collaborated on The Accentism Project, an ongoing initiative which aims to promote discussion about language-based prejudice and discrimination in all its forms. The project raises awareness of discrimination and seeks to intervene in public discourse on accents, dialects and languages, and the negative judgements that may occur. The project website (details provided at the end of the interview) encourages people to submit their own stories and examples of discrimination based on how they speak. Example stories from the website have been included throughout this interview.

Whilst doing my teacher training, the lead lecturer suggested that I attend lessons so I wouldn't speak with a Yorkshire accent. I didn't.

(accentism.org/stories)

Laura: Can you briefly summarise what The Accentism Project is all about?

Erin Carrie: The aim of the project is to start the discussion and to hear from real people about any instances where they've felt negatively judged or unfairly treated based on the way that they speak.

\section{Affiliation}

Laura Paterson: Open University, UK. email: laura.paterson@open.ac.uk 
It's not enough just to talk about such discrimination, so we want to work with various groups within society via community workshops where we bring this issue to the fore, get people to interrogate their own views and their own biases, and hopefully change their perspective on language. Essentially, we want to show people that there is no linguistic basis for discriminatory judgements. We also want to intervene in institutional contexts and look at policies about language and the use of language within institutions, as well as training staff in terms of monitoring their own biases and making sure that they are not using language as a proxy for making discriminatory judgements about people. We're talking to the Equality and Diversity team at Manchester Metropolitan University to see how we can develop training in this area. It's early days but it's certainly something that we are keen to develop.

Rob Drummond: It's also about providing evidence for what is happening. A lot of our work has always indirectly been to do with some sort of discrimination or negative judgements. It's all very well for us to say this is happening, but we want to develop our own evidence base that accentism is a genuine thing for us to be dealing with. The project gives us real examples that can generate discussion, but it also gives us something to target our interventions towards. It can help us to start to build a picture of the areas where discrimination actually takes place, rather than guess or assume that it does.

EC: $\quad$ That's the tricky thing; historically, people have relied on anecdotes, so accentism might not seem as much of an issue as it really is, so we need to gather evidence through stories, through workshops, and through language attitude tests in those workshops to show people that this is actually happening, rather than just talk about accentism in the abstract.

RD: We also think it's quite important as linguists that we bring our skills to the subject. It is quite easy to have debates and discussions about language prejudice without really understanding the linguistic basis of it all. There are studies around which are a little bit too anecdotal and do not fully grasp the underlying linguistic facts and what has gone before; there is a whole literature out there on language variation and attitudes. I think because we

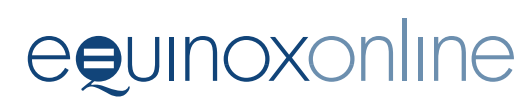


engage with that it puts us in a stronger position to properly challenge accentism.

EC: $\quad$ It's not a new area of study, but a lot of what has been published leans towards being more descriptive and it's great that as linguists we can investigate this topic and analyse such an interesting issue in greater depths. But I think it is our duty as academics to then intervene and try to change the discourse around accents, dialects, etc. rather than observing it from afar.

I had to raise an issue with higher management in a big multinational because they said we couldn't speak any language other than in English while on shift (illegal) and that we would lose bonuses or get fired if we did (highly illegal). They even dared to put it in writing and send an email stating ALL of it. Of course, they had to back down. But out of a team of 50-60 people ( $90 \%$ foreigners), nobody else was brave enough to complain. Not even foreign managers.

(accentism.org/stories)

Laura: What drew you into this area of research?

RD: I did my PhD on sociolinguistic variation in a second language, looking at Polish migrants who lived in Manchester and the extent to which they acquired a Manchester accent. That got me interested in the idea that different accents are perceived in different ways, and also coming from an English language teaching background and a teacher training background I was very aware of trainee teachers being conscious of their accents and whether they would be suitable for the classroom. So I knew there was a discourse around that, so it was always of interest. Then I did a big project working with young people who had been excluded from school - in a pupil referral unit - and that's where it all crystallised. I was interested in regional accent diversity, but also the idea of youth language and the negative perception of the way young people speak. There is a lot of discourse around young people making themselves unemployable because of the way they use language and that put things into focus for me because it is sometimes strange when, like me, you come from a background (I'm from southeast England) where you don't tend to face accent prejudice in the area you live or work.

EC: It was a similar start for me. We both started working with second language users of English, but my focus was on learners in an L1 context - so learning English from their home countries

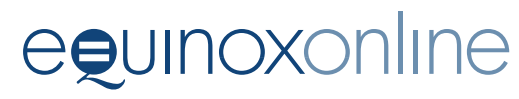


- and learner attitudes towards the models they were exposed to, the connotations of speaking with an RP accent or an American accent, and how learners wanted to be perceived in their second language. So it brought in issues of identity in the second language. Then since my $\mathrm{PhD}$ we have been developing another project here - Manchester Voices - which is all about accent, dialect and identity, and I've been looking at attitudes to language in the UK, and specifically in the north of England. Some really interesting stories have come up as part of Manchester Voices too; people talking about where they belong, how linked their accent is to where they live, and feeling like they are judged for having a northern accent. They have their own stereotypes of southerners, southerners have their stereotypes of northerners; that is the perception at least. People have talked about the way their accents were 'knocked out of them'. The Accentism Project is just an extension of our interest in this particular theme.

RD: I think we were both researching accentism without giving it a name, and so about a year ago we realised that this was what it was. To give some more detail about Manchester Voices, we've just received a grant from the Arts and Humanities Research Council to fund the project for the next three years. While The Accentism Project is not funded directly, the grant sits above all of the things we do. So the whole project will get a boost from Manchester Voices.

EC: $\quad$ I think the thing that links The Accentism Project and Manchester Voices is that ultimately we are trying to celebrate diversity and to challenge negative perceptions and inequality when it comes to not just regional accents, because a lot of the research will focus on regional accents, but second language accents and other minority or non-standard varieties of English as well. So there are threads across the things that we do.

Once my older brother took a taxi in Madrid. He often goes to the capital for business. During the trip he was called to his mobile phone. When he heard him talking, the taxi driver stopped and ordered him to get out of the cab. He had recognised that he was speaking Catalan.

(accentism.org/stories)

Laura: When did the project start and do you have a defined endpoint when you are going to stop collecting data? 
EC: We launched in February 2018 and the project is ongoing. We're not planning to stop it. We want it to be available online because the website does not just collect people's stories, it is also a hub where we can post research or media stories or podcasts so that people can learn more about the issue if they want to. So it will continue to run and we have also got a Twitter feed (details are provided at the end of this interview) where we actually have a lot more discussion. So there is no planned endpoint.

Laura: How do you plan to analyse the data that you've collected?

EC: We didn't actually set the website up with the intention of gathering data. It was about promoting discussion and having a place where we could start to pull together stories on this particular subject. However, when we ask people for their stories we do let them know that we may well use them for research purposes. So eventually when we've got a large body of stories we will do some sort of corpus or discourse analysis.

RD: It will be some sort of discourse analysis, thematic analysis. The primary aim was to have a place for general discussion; so the website is really the public-facing part of what we do.

EC: I think it's likely that we will focus more on data that we generate through workshops. So the stories give us a way in, as a sort of discussion point, and then we will be doing activities and things during workshops and training units that will serve as more the type of data that we want to work with.

RD: We will be going into schools soon as well. The project ties in with what is covered on A-Level English Language so we're going to combine those; we will go in and give our talks, but then run a workshop and use what we get from that as actual data.

Laura: What has been the most surprising thing about undertaking The Accentism Project?

EC: The main thing that I've learned is that nobody is safe from language-based prejudice; it works in various directions. I think there is an assumption that people with more standard accents are immune somehow from prejudice, but we've got various reports from people who claim to be RP speakers, or near RP speakers, who have really had a hard time. They have been bullied, they have been called terrible things, or they have been told that they

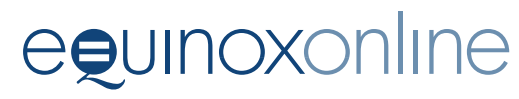


are 'posh' in a very derogatory way. I think there is an assumption that people with regional accents feel that discrimination works one way, kind of downwards from more standard to less, but actually the stereotypes work both ways.

RD: $\quad$ Some of the stories from universities as well. From places where you would think people would be quite tolerant. There are quite a lot of stories from students.

EC: $\quad$ Teachers, students, lecturers, discrimination works in all sorts of directions. One of the initial stories that we had was from a lecturer in linguistics. After one of his earlier lectures in his career, a student came up and said they thought it was disgraceful that someone with his accent - a Geordie accent - was teaching linguistics at university. There are a couple of examples from sociolinguistics conferences where people have been told to stop talking because their accent is annoying, someone was challenged on their Scottish accent, and one of the sociolinguists in the audience said 'yeah, you like to think you have your own language in Scotland, don't you?' and things like that. You would expect a sociolinguistics conference to be the safest space. So there are a few stories in an educational context which are really quite striking. On the website we have story tags. So every time we upload a story to the website we link it to a particular theme or we pull out keywords and that way you can start to see trends developing in the larger body of stories.

Today I spoke to a GP who said that if they heard a Scottish accent from a new patient, they would know that this person had a problem with alcohol or drugs. They said this was not prejudice, but merely a reflection of the location where their practice is based, and the fact that in their experience $100 \%$ of the Scottish people in this location have issues with alcoholism or other substance abuse.

(accentism.org/stories)

Laura: What tends to be reported more, people being targeted because their accents indicate that they are a non-native speaker or people being abused because they speak non-standard (regional) varieties of English?

RD: It is mostly regional in terms of accents. But we have had stories from other countries; the project is multilingual. 
EC: In Spain, accentism is a really big issue as well; we've been contacted by Spanish journalists to comment on accent discrimination. We've got stories from France, stories from Germany, stories from Greek Cypriots. The story tags show that various nationalities are represented on the website. We've got quite a balance between regional accents and second language accents. I think there is some intersectionality going on here too. Negative judgements will be made against regional and second language accents, but if you are a second language speaker who uses a regional accent it's interesting to consider whether there is a double prejudice there.

Laura: How can people get involved with The Accentism Project?

RD: $\quad$ First thing is just to share their stories. We are very careful to make sure that people know we are interested in prejudice, discrimination, stereotyping, and negative judgements as well. Any sort of judgement based on language we're interested in. I think people have a lot of those stories. The only thing we're not interested in is people peddling what we are trying to fight. We had someone who was basically being discriminatory and that wasn't what we were after.

EC: $\quad$ Yeah, we've had a few stories that perpetuate the issue and some people have said 'oh, but implicit prejudice or bias can also favour some people so it can also be positive. Your accent might work for you if you've got a regional accent in a particular job'. But I think the point that we always come back to is that if it works for some people then it works against other people, regardless of the context. The actual dynamics of that particular context may differ, but favouring one accent inevitably means disfavouring others. So the old call centre example of people with regional accents being preferred because they sound friendlier or trustworthy means that maybe an RP speaker in that context would feel disadvantaged because people don't respond well to them.

RD: While we say 'regional', we are also challenging the idea that there is such a thing as a regional accent. My accent won't be seen as regional because I come from the south. There isn't any context where I think my accent would be classed as regional, even though the southeast of England is a region like anywhere else.

\section{eevinoxonlıne}


EC: 'Neutral', that comes up a lot too, and the idea of not having an accent. That is a real issue and in terms of discourse that is something that we want to challenge.

I was educated in a private school and speak almost with RP; however, throughout my whole life I have received comments like 'who do you think you are with that accent?' and 'you can't be from Newcastle.'

(accentism.org/stories)

RD: Similarly, the whole issue of accent reduction. It is not possible; by undertaking accent reduction, you are just shifting and changing your accent to a different accent.

EC: This is another thing we have to mention, because we have mentioned the schools and training for institutions, but we are also talking to other bodies and industries, and because accent reduction is quite a contentious industry. I've been working with editors and proofreaders and recently wrote two blog posts for the Society for Editors and Proofreaders about some of the discourse that's used within that profession. This idea that something is 'better' or 'worse', that something is more 'correct', or that people should have a 'clean' and 'clear' style of writing, it's all based on a certain norm, a standard. I think we've got to really challenge these professions or industries and question whose voices they are actually promoting and whose they're silencing. It is really useful to get anyone working with language, in any sort of monitoring or coaching role, to be much more aware of the discourse that they're using.

RD: If you speak to accent reduction professionals, they say 'well, there's a market for it so we're trying to help'. So in our job we have to do two things; we have to, on the one hand, help celebrate diversity, but on the other hand we have to challenge some of the prevailing views within society. I've had this with the young people I work with; it's all very well telling young people that the way they speak is fine and should be championed, and why should they conform to an arbitrary standard, but that's a very naïve thing to say in some respects. I'll have teachers telling me 'that's fine, but they are going to be judged'. Saying all accents are equally valid and what accent you have shouldn't matter is well intended, but your accent does matter to some people so we have

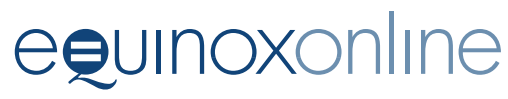


to challenge that side of things. So voice coaches, accent reduction professionals, they'll say they are fulfilling a need. There is no shortage of clients who'll say 'I need to get rid of this accent because it's harming my employment possibilities'. So we need to challenge that whole discourse.

My son's American accent was relentlessly (and badly) mocked and imitated in his secondary schools here in London, and it made him absolutely miserable. This naturally made the other kids do it more. He has taken badly against the country as a whole as a result - a stereotyping overreaction in itself. Prejudice begets prejudice. He hates it here and can't wait to be old enough to move away.

(accentism.org/stories)

To get involved with The Accentism Project, visit the project's website at: https://accentism.org. You can submit your own stories of accent discrimination and read the stories submitted by others. The web pages on related research and accentism in the media are also good sources of teaching and research materials. The website is a hub of information about accentism open to everyone and it is designed to spark wider discussions. To join in the conversation on Twitter follow @AccentismProj or use \#Accentism. For more information about the Manchester Voices project, which is also run by Erin and Rob, see https://www.manchestervoices.org/ or use \#McrVoices.

Laura L. Paterson

April 2019 